\title{
사실적인 리라이팅 시스템 연구
}

1. 서론

II. 개념과 기술적 동향

III. 어클루전을 이용한 사실적인 리라이팅 시스템

IV. 결론

참고문헌

ABSTRACT

\section{박재욱}

\section{초 록}

$3 \mathrm{D}$ 애니메이션에서의 라이팅 작업은 많은 노동력과 시간이 걸리는 일이다. 예 를 들어서 2014년에 글로벌하게 배급된 극장용 애니메이션 Postman Pat The Movie에서는 60여명의 라이팅 아티스트가 필요했으며, 이 아티스트들은 샷의 피드 백에 빠르게 대응해야 하지만, 복잡한 샷들은 많은 렌더시간을 필요로 해서 테스트 렌더링을 하며 작업 대응을 하기 힘든 문제가 있었다. 2005년 이후 이러한 상황에 대처하고자 리라이팅 기법을 사용하는 경우가 있었으나, 하지만, 기존의 리라이팅 방식으로는 그림자를 얻어낼 수가 없기 때문에 사실적이거나 자연스러운 결과물을 얻어낼수가 없어서 국내 애니메이션 제작에서 거의 사용되지 못하였다.

본 논문에서는 Rasterization된 앰비언트 어클루전을 각 라이트 별로 리라이팅 계산에 접목시켜 빠른 계산을 유지하면서도 사실적인 퀄러티를 얻어낼 수 있는 리 라이팅 시스템을 구현하였다. 이 리라이팅 시스템은 2014년 글로벌하게 개봉된 헐 리우드 애니메이션인 Postman Pat : The Movie에 채택되어 성공적인 제작을 해내 는데 큰 기여를 하였다. 이후 애니메이션 제작에 이 방법이 더 많이 활용되어 다른 제작사에서도 제작비의 절감과 함께 좀 더 완성도 있는 결과물을 제작할 수 있는 계기가 되길 바란다.

주제어 : 리라이팅, 앰비언트 어클루전, 렌더링 


\section{I. 서론}

$3 \mathrm{D}$ 애니메이션에서의 라이팅 작업은 많은 노동력과 시간이 걸 리는 일이다. 예를 들어서 2014년에 글로벌하게 배급된 극장용 애니메이션 Postman Pat The Movie에서는 60여명의 라이팅 아티 스트가 필요했으며, 이 아티스트들은 샷의 피드백에 빠르게 대응 해야 하지만, 복잡한 삿들은 많은 렌더링 시간을 필요로 해서 테 스트 렌더링을 하며 작업 대응을 하기 힘든 문제가 있었다. 라이 팅 아티스트들은 때로는 프리뷰용 렌더링 시간을 줄이기 위해서 샘플링을 낮추거나 셰이더를 단순한 것으로 교체해서 사용하여야 했다. 이 경우는 정확한 결과물을 볼 수가 없어서 아티스트들의 예측에 의존해야 한다는 문제가 있었고, 고품질 렌더링은 프레 임당 수 시간 이상의 시간이 소요된다는 문제가 있었다.

2005년 이후 이러한 상황에 대처하고자 리라이팅 기법을 사용 하는 경우가 있었으나, 기존의 리라이팅 기법으로는 그림자가 생 기지 않아서 복잡한 형태의 오브젝트에는 디테일이 떨어져 보이 기 때문에 실제 애니메이션 제작에 적극적으로 적용된 사례가 경 우가 많지 않았다.

본 논문에서는 렌더패스를 이용한 리라이팅에 있어서 각 조명 별로 앰비언트 어클루전을 복합적으로 사용하여 아주 복잡한 샷 도 최종 결과물에 가까운 퀄러티로 빠르게 조절할 수 있는 방법 을 제시하고자 한다.

\section{II. 개념과 기술적 동향}

\section{1. 렌더링 프로세스 개요}

애니메이션 제작에 사용되는 $3 \mathrm{D}$ 렌더링은 다음과 같은 프로세 스로 진행된다. 


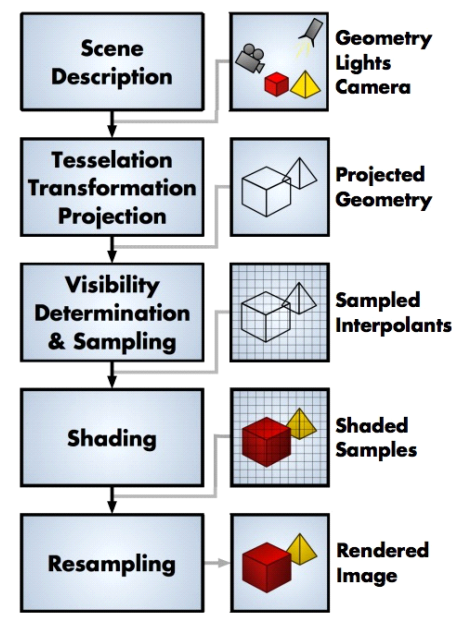

그림 1. 렌더링 프로세스 개요1)

1) 상대 좌표계로 변환 : 먼저 3차원적인 장면(Scene)을 카메 라 시점에서 보이는 2 차원적인 이미지로 번환하는 과정을 거쳐야 한다. 이 과정으로 3 차원적인 절대좌표계에 있는 오브젝트가 카 메라 시점의 상대 좌표계로 변환된다. 이 과정에서 NURBS나 Subdivision 오브젝트들은 폴리곤으로 Tessellation 된 후에 상 대 좌표계로 변환된다.

2) 가시성 결정 및 샘플링 : 각각의 기하학적 오브젝트들이 스 크린 스페이스(Screen Space)의 상대 좌표계로 변환되고 난 후에 는 렌더링 소프트웨어가 공간상의 어느 지점이 이미지의 각 샘플 위치와 연계되는지 결정해야 한다. 이때 Z-buffer나 레이 트레이 싱 알고리즘을 사용하여 어느 기하학적 오브젝트가 카메라에 가 까이 있어서 보이고 어떤 오브젝트가 뒤에 가려지는지를 각 샘플 위치별로 계산하는데, 이 계산은 대용량의 정리되지 않은 데이터 를 처리해서 스크린 스페이스상의 정리된 데이터로 변환하는 대

1) J. M. Ragan-Kelley, Practical interactive lighting design for RenderMan scenes, Undergraduate thesis, Stanford University,2004, pp.4. 
용량의 작업을 수반한다.

3) 라이팅 : 각 샘플별로 셰이딩할 포인트가 정해지면, 렌더링 소프트웨어는 라잇과 셰이딩 포인트와의 거리, 각도 등을 이용해 셰이더에서 지정한 방식대로 계산해서 색을 도출해낸다. 셰이더 에서는 이때 디퓨즈, 스페큘러, 반사, 굴절, 등의 셰이딩 요소들 을 각각 계산하는데, 이때의 각각의 요소들은 레스터라이즈된 이 미지로 별도로 저장될 수도 있다.

4) 리샘플링 : 색이 계산된 각 요소들은 화면상의 픽셀의 색을 도출하기 위해 합쳐져서 최종적인 화면상의 색이 도출된다.

애니메이션 제작에서 라이팅 아티스트들은, 장면에 기본적인 조명을 배치한 후 렌더링을 걸어보고, 피드백에 따라 조명의 색 과 밝기를 조절하거나, 혹은 조명을 추가한다. 라이팅 아티스트 가 수정한 장면은 렌더링을 걸어 보아야만 결과를 확인하고 추가 적인 수정을 할 수 있는데, 대규모 장면에서는 수정을 확인하기 위한 렌더링에 몇 시간씩 기다려야 하기 때문에 불가피하게 작업 효율이 떨어지게 된다.

이러한 라이팅 아티스트의 수정확인을 위한 렌더링은 장면내 오브젝트 구조가 바뀌지 않는 같은 장면을 렌더링 하는 것이므로 렌더링 프로세스 단계상 라이팅의 일부 계산과 리샘플링 단계에 서만 변화가 반영이 될 뿐이고, 계산이 오래 걸리는 상대좌표계 변환과, 가시성결정 및 샘플링은 앞서 계산한 것과 똑같은 계산 을 반복하는 것을 알 수 있다.

따라서 렌더링 프로세스상의 라이팅 단계에서 이미 레스터라이 즈(Rasterization)가 된 셰이딩 요소들을 따로 이미지로 저장한 후 캐시화해서 재사용 한다면, 수정용 렌더링을 다시 할 때 대부 분의 계산을 재사용하여 획기적인 렌더링 시간 단축이 가능해진 다.

퐁 셰이딩의 일루미네이션 루프 수식을 이용해서 Standard 3D lighting에서 사용되는 각 요소들을 살펴보고 이중 리라이팅 (re-lighting)을 할 때도 재계산 없이 사용할 수 있는 것과 다시 계산해야 하는 것을 살펴보고자 한다.2) 


$$
\begin{gathered}
I_{\mathrm{p}}=k_{\mathrm{a}} i_{\mathrm{a}}+\sum_{m \in \text { lights }}\left(k_{\mathrm{d}}\left(\hat{L}_{m} \cdot \hat{N}\right) i_{m, \mathrm{~d}}+k_{\mathrm{s}}\left(\hat{R}_{m} \cdot \hat{V}\right)^{\alpha} i_{m, \mathrm{~s}}\right) . \\
\text { 표 1. 일루미네이션 루프 수식 }
\end{gathered}
$$

리라이팅을 위해서는 라이팅의 독립적 성분을 카메라 시점으로 이미지 캐쉬화를 먼저 한다. 이 이미지들은 시작 단계에서 한번 만 계산되어 텍스춰 이미지의 형태로 캐쉬화 되고, 이미지를 이 용해서 리라이팅을 계산한다. ${ }^{3)}$

$3 \mathrm{D}$ 애니메이션 제작을 위한 대부분의 상용 소프트웨어를 통해 서 렌더링을 하였다면, 위 수식에서 컬러맵에 해당되는 $\mathrm{Kd}$ 와 스 페큘러맵에 해당되는 Ks는 렌더링된 스크린 스페이스에서 그대로 재사용이 가능하다.

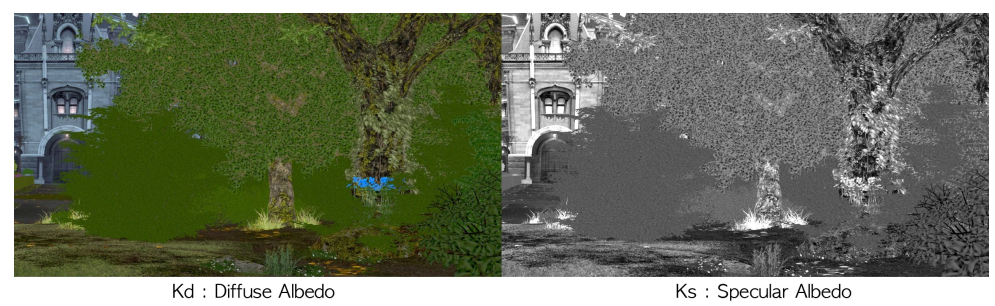

그림 2. 스크린 스페이스에서의 $\mathrm{Kd}, \mathrm{Ks}$

그렇다면, 리라이팅 연산에서는 디퓨즈 셰이딩과, 스페큘러 셰 이딩을 다시 계산해야 하는데, 디퓨즈 연산을 의미하는 $\left(\hat{L}_{m} \cdot \hat{N}\right) i_{m, \mathrm{~d}}$ 와 스페큘러 연산을 의미하는 $\left(\hat{R}_{m} \cdot \hat{V}\right)^{\alpha} i_{m, \mathrm{~s}}$ 이 주요 리라이팅 연산이 되는데, 이를 위해서 는 Shading Point를 구하기 위한 P와 P에서의 법선벡터인 N이 스

2) B. T. Phong, Illumination for computer generated pictures, Communications of the ACM, (1975.6) pp. 311-317

3 ) 김순현외 2 명. 『영상기반 실시간 재조명 렌더링 시스템」, 『한국HCI학회논문지 \lrcorner , 2권 1호(2007), pp.25 31. 
크린 스페이스의 이미지 형태로 필요하게 된다.

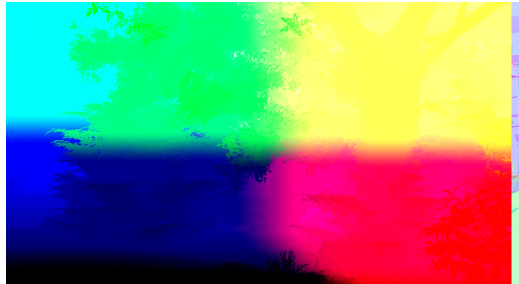

P: Position

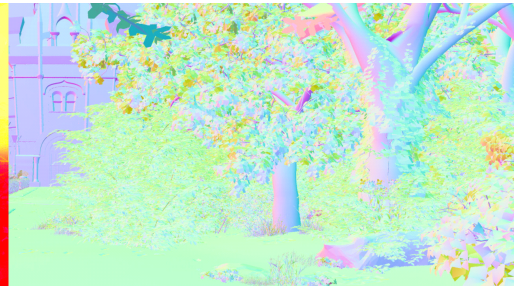

$\mathrm{N}$ : Normal Vector

그림 3. 스크린 스페이스에서의 P, N

이 이미지들이 있으면, 리라이팅의 가상의 추가 조명을 설정하 고 그 조명의 위치좌표와 밝기를 설정하면 B.T. Phong의 Illumination 수식에서 필요한 부분을 모두 충족시키기 때문에 디퓨즈 연산과 스페큘러 연산이 가능해진다.

리라이팅 기법은 조명에 의한 디퓨즈, 스페큘러를 제외한 나머 지 요소들을 Rasterization하고, 그 기반 위에 이미 Rasterization되어있는 P와 $\mathrm{N}$ 을 사용해서 디퓨즈와 스페큘러를 빠른 시간에 계산할 수 있음을 알수 있다.

이 방법을 애니메이션 제작 프로덕션에 적용하면 아래와 같은 상황을 가정해 볼 수 있다.

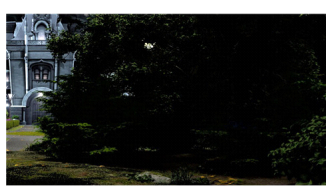

리라이팅 적용전

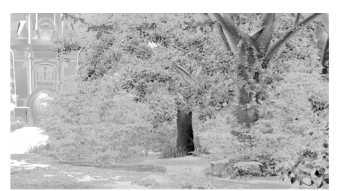

리라이팅 계산 이미지

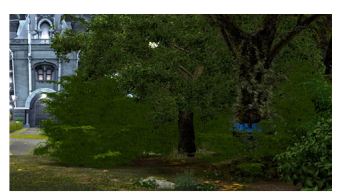

리라이팅 적용 이미지

그림 4. 기존 방식 리라이팅 적용 예제

<그림 4>의 좌측 이미지는 3 천 5 백만개의 폴리곤으로 구성되어 프레임당 렌더시간이 1 시간 20 분이 걸린 이미지 이다.

이러한 장면을 제작하는 라이팅 아티스트는 테스트 렌더를 기 다려야 하는 시간도 길 뿐 아니라, 라이팅에 대한 수정이 들어왔 을때 새로 렌더링을 거는데 드는 시간도 아주 길다. 
하지만 리라이팅 기법에 기반해서 P, N을 사용해서 리라이팅을 계산하면 <그림 4 의> 중간 이미지와 같은 결과값이 나온다. 이렇 게 리라이팅을 계산하여 오른쪽 이미지를 얻어내는데 걸리는 시 간은 3 초 정도였다. 오리지널 렌더링에 걸린 시간이 1 시간 20 분 이었던것과 비교하면 1600 배에 달하는 속도 향상을 얻을 수 있 다. 이토록 리라이팅 기법을 애니메이션 제작 실무에 사용하면 렌더링 시간을 획기적으로 향상시키고, 이로 인해, 라이팅 아티 스트들의 테스트 작업과, 샷 수정작업에 대한 시간과 예산을 크 게 단축시킬 수 있게 된다.

리라이팅 기법은 1000 배가 넘어가는 획기적인 시간단축이라는 이점에 반해 한계점이 공존하는데, 이는 모든 셰이딩이 단지 포 지션과 노멀에 의해서만 이루어지므로 그림자가 생성될 수가 없 다. CGI 라이팅 작업에서 그림자는 현실감 조성에 있어서 매우 중요한 역할을 하므로, 현재까지의 리라이팅 기법은 그림자가 없 다는 문제에 대한 보완이 필요하다.

\section{III. 어클루전을 이용한 사실적인 리라이팅 시스템}

리라이팅 기법의 비사실성에 대한 보완은 리라이팅 연산시, 라 잇 위치의 변화에 따른 추가적인 연산 없이 재사용이 가능한 요 소이어야 하며, 스크린 스페이스 기반 이미지로 표현 가능한 것 이어야 한다.

2014년 박재욱, 김윤정은 논문 'Ambient Occlusion을 이용한 GI 대체기법 연구' 에서 '앰비언트 어클루전(Ambient Occlusion)의 함수를 Rasterization방식에서 사용하는 Illumination Loop 식에 접목시켜서 글로벌 일루미네이션처럼 다 양한 색의 조명을 반영하면서도 Rasterization처럼 빨리 렌더링 할 수 있는 알고리즘 수식' 을 제시하였다.

따라서 위의 조건들을 충족시키는 앰비언트 어클루전(Ambient Occlusion)을 리라이팅 기법안에 효과적으로 적용시켜 빠르고 사 실적인 리라이팅 연산을 얻어내는 방법을 본 논문에서 제안하고 
자 한다.

박재욱, 김윤정(2014)에 따르면 B.T. Phong의 Illumination 수 식에 앰비언트 어클루전이 적용된 수식은 아래와 같다. ${ }^{4)}$

$$
\begin{gathered}
I_{\mathrm{p}}=k_{\mathrm{a}} i_{\mathrm{a}}+\sum_{m \in \text { lights }}\left(k_{\mathrm{d}}\left(\hat{L}_{m} \cdot \hat{N}\right) i_{m, \mathrm{~d}}\left(1-\left(1-A_{\bar{p}}\right) i_{m, \mathrm{o}}\right)+k_{\mathrm{s}}\left(\hat{R}_{m} \cdot \hat{V}\right)^{\alpha} i_{m, \mathrm{~s}}\right) \\
\text { 표 2. 어클루전 일루미네이션 루프 수식 }
\end{gathered}
$$

이 식에 따르면 앰비언트 어클루전인 $\left(1-\left(1-A_{\bar{p}}\right) i_{m, \mathrm{o}}\right)$ 은 $\mathrm{Kd}$ 와 디퓨즈 셰이딩에 곱해지면 된다. 앰비언트 어클루전도 재사 용이 가능한 요소이므로, 한번 렌더링을 해 놓고나면 인터렉티브 한 리라이팅을 하는데 있어서 추가적인 계산이 필요하지 않게 된 다. 이 방식을 리라이팅에 적용하게 되면 하면 아래와 같은 이 미지를 얻을 수 있다.

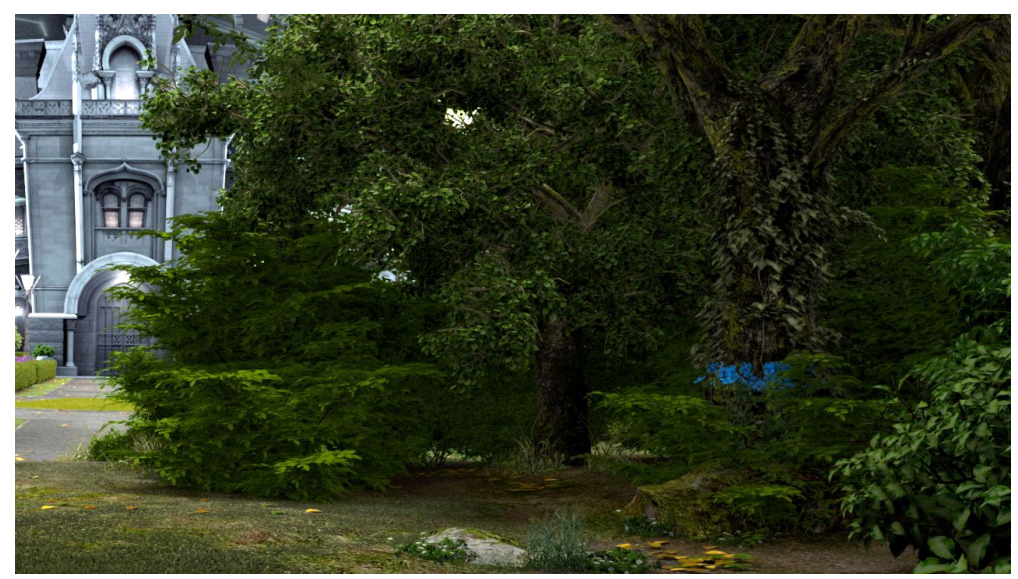

<그림 5> 본 논문에서 제안한 방식을 이용한 리라이팅 결과 이미지

기존의 방식과 비교해서 지오메트리의 디테일이 아주 잘 살아 남을 알 수 있다. 리라이팅 계산시 각각의 조명을 계산할 때 이

4) 박재욱, 김윤정, 「Ambient Occlusion을 이용한 Global Illumination 대체기법 연구」, 「만화애니메이션연구」36권 (2014) pp.501. 
미 Rasterization되어있는 앰비언트 어클루전을 곱해줌으로써 빠 른 리라이팅을 유지하면서도 지오메트리 형태의 디테일을 표현할 수 있게 되었다.

기존 리라이팅 시스템을 이용한 이미지와 본 논문에서 제안하 는 리라이팅 방식을 이용한 이미지를 비교하면 아래와 같다.

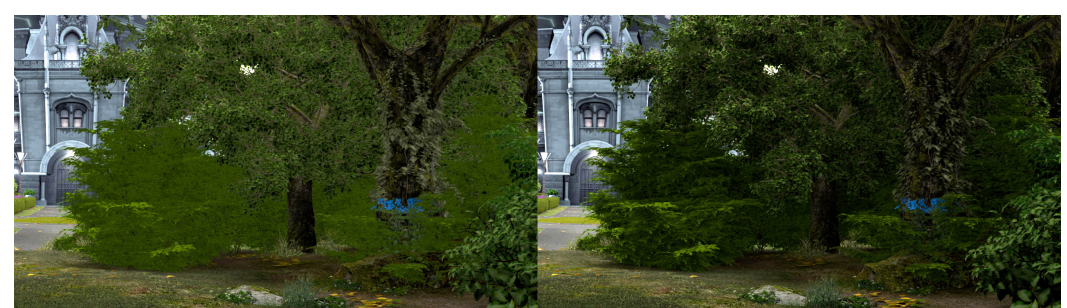

기존 방식의 리라이팅. 렌더시간 3초

본 논문에서 제시하는 방식의 리라이팅. 렌더시간 4초

그림 6. 기존의 리라이팅 이미지와 본 논문에서 제안하는 리라이팅 이미지의 비교

기존 방식의 리라이팅으로 렌더된 이미지와 본 논문에서 제시 하는 방식으로 렌더된 이미지를 비교하면 현실감과 디테일이 확 살아남을 볼 수 있다. 그러면서도 렌더링 시간은 여전히 빠르게 유지하고 있다.

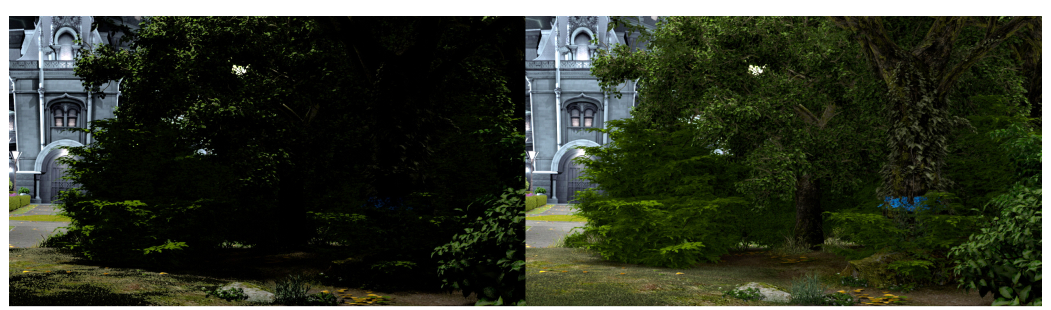

오리지널 렌더링. 렌더시간 1 시간 20분

본 논문에서 제시하는 방식의 리라이팅. 렌더시간 4 초

그림 7. 리라이팅 전후 렌더시간 비교

\section{IV. 결론}

$3 \mathrm{D}$ 애니메이션에서의 리라이팅 방식의 장단점을 간략히 정리하 
면 다음과 같다.

리라이팅은 렌더링 과정에서 레스터라이즈된 법선벡터, 포지션 정보를 이용하여 추가적인 라이트를 매우 빠른 시간 안에 얻을 수 있는 렌더 방식이다. 이는 무거운 장면도 적은 메모리와 1000 여배 이상 빠른 계산으로 애니메이션 제작에 있어서 획기적인 제 작기간 단축과 예산절약의 가능성을 보여준다. 하지만, 기존의 리라이팅 방식으로는 그림자를 얻어낼 수가 없기 때문에 사실적 이거나 자연스러운 결과물을 얻어낼 수가 없어서 국내 애니메이 션 제작에서 거의 사용되지 않는 것이 현실이다.

본 논문에서는 레스터라이즈된 앰비언트 어클루전을 각 라이트 별로 리라이팅 계산에 접목시켜 빠른 계산을 유지하면서도 사실 적인 퀄러티를 얻어낼 수 있는 리라이팅 시스템을 구현하였다. 이 리라이팅 시스템은 2014년 글로벌하게 개봉된 헐리우드 애니 메이션인 Postman Pat : The Movie에 채택되어 성공적인 제작을 해내는데 큰 기여를 하였다. Postman Pat : The Movie의 평균 렌 더링 시간은 프레임당 1 시간 30 분으로써 조명 결과 확인에 수십 분에서 몇 시간씩 걸리던 터라, 획기적인 제작방식의 전환 없이 는 개봉 전까지 제작완료가 불가능 하던 상황이었는데, 이때 본 논문의 리라이팅 방식을 도입함으로써 한번 렌더한 이미지는 조 명 수정 결과 확인이 수초 이내에 이루어짐으로써 제작 시간 단 축에 큰 도움이 됨을 확인하였다.

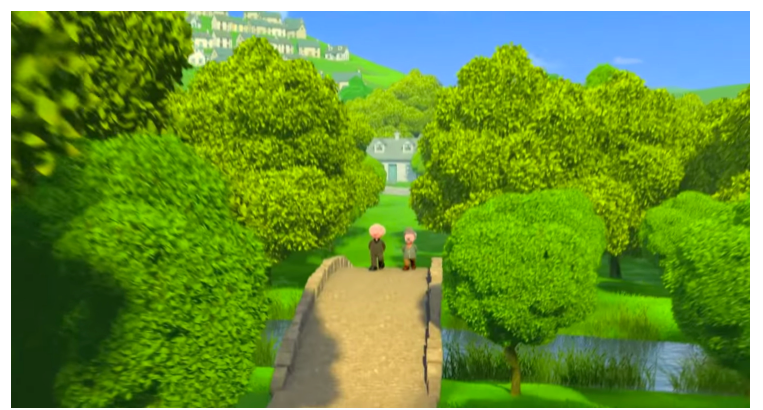

그림 8. 본 논문에서 제시하는 리라이팅 시스템이 적용된 상업 애니메이션 Postman PAT: The Movie 
아직 리라이팅 시스템에서 반사, 굴절 등의 재계산은 사용될수 없다. 애니메이션용 $3 \mathrm{D}$ 렌더링에서 반사와 굴절의 비중이 갈수록 높아짐에 있어서 이는 큰 제한점이라 볼 수 있다. 앞으로의 연구 는 리라이팅에 반사와 굴절의 계산이 가능할 수 있도록 이 분야 의 연구가 확대되어져야 한다고 생각한다.

\section{참고문헌}

김순현외 2명(2007). 『영상기반 실시간 재조명 렌더링 시스템」, 『한국 $\mathrm{HCI}$ 학회논문지」, 2권 1호, 25 31.

박재욱, 김윤정(2014), 「Ambient Occlusion을 이용한 Global Illumination 대체기법 연구」, 「만화애니메이션연구」36권 p.501.

J. M. Ragan-Kelley(2004), "Practical interactive lighting design for RenderMan scenes」, Undergraduate thesis, Stanford University, p.4.

B. T. Phong(1975.6), Illumination for computer generated pictures, Communications of the ACM SIGGRAPH, 311-317

F. Pellacini, K. Vvidimce, A. Lefohn, A. Mohr, M.Leone, and J. Warren, "Lpics: a hybrid 31

hardware-accelerated relighting engine for computer cinematography", in Proceedings of ACM SIGGRAPH 2005, pp. 464 470, 2005. 


\section{ABSTRACT \\ Realistic Re-lighting System with Occlusion}

Park, Jae-Wook

Lighting work on 3D animation requires much time and labor. For example, about 60 lighting artists were needed for the theater animation named Postman Pat the Movie globally distributed in 2014. These artists were needed to rapidly respond with shot feedback. However, complicated shots required much of rendering time. Therefore, it was difficult to correspond the work in the middle of test rendering. After 2005, re-lighting techniques were developed to cope with such situations. However, it was not feasible to create shadow with current re-lighting technique which doesn' $t$ make natural or realistic result. This paper has realized relighting system that could realistic quality while maintaining fast calculation by applying rasterized ambient occlusion to the relighting calculation of each of the lights. This relighting system has been used for the Hollywood animation titled "Postman Pat: The Movie" globally released in 2014. It is anticipated for this method to be more widely used for animation manufacture that other manufacturers can reduce expenses and create well completed output in the future.

Key Word : re-lighting, ambient occlusion, rendering

박재욱

Giant Step VFX Supervisor (135-010) 서울특별시 강남구 논현동 90-4

Tel : 010-7128-7303

hound007@gmail.com

논문투고일 : 2015.02.01.

심사종료일 : 2015.02.27.

게재확정일 : 2015.03.04. 